\title{
Current treatment of acute perforated diverticulitis: the role of damage control surgery
}

This article was published in the following Dove Press journal: Journal of Inflammation Research

\section{Maurizio Zizzo ${ }^{1,2}$ \\ Antonio Manenti ${ }^{3}$ \\ Lara Ugoletti ${ }^{\prime}$}

'Department of Oncology and Advanced Technologies, Surgical Oncology Unit, AUSL-IRCCS of Reggio Emilia - Arcispedale Santa Maria Nuova, Reggio Emilia, Italy; ${ }^{2}$ Clinical and Experimental Medicine PhD Program, University of Modena and Reggio Emilia, Modena, Italy; ${ }^{3}$ Department of General Surgery, Azienda Ospedaliero-Universitaria Policlinico, Modena, Italy
Correspondence: Maurizio Zizzo Department of Oncology and Advanced Technologies, Surgical Oncology Unit, AUSL-IRCCS of Reggio Emilia Arcispedale Santa Maria Nuova, Risorgimento Avenue 80, 42123, Reggio Emilia, Italy

Tel +39052 2296372

Fax +39052 2295779

Email zizzomaurizio@gmail.com

\section{Dear editor}

We were struck by Ceresoli et al's ${ }^{1}$ article published in Journal of Inflammation Research in May 2018. The aim of the review was to investigate the role of inflammation in diverticular disease and in mild and complicated acute diverticulitis with particular attention to the current research and treatment perspectives. ${ }^{1}$ Based on the solid collaboration of the authors with the World Society of Emergency Surgery (WSES), a worldwide reference in the management of emergency surgical diseases, our attention was focused on the Damage Control Surgery (DCS) paragraph.

After a brief description of the DCS procedure, the authors introduced the experience of Sohn et al, ${ }^{2}$ with the aim of presenting the results of the application of DCS in acute perforated diverticulitis. ${ }^{1}$ Previously, $\mathrm{we}^{3}$ criticized the patient selection criteria adopted by Sohn et al. Therefore, we would like to stress some issues in order to underline the importance of correct patient selection criteria for DCS, an emergency surgical procedure useful to stop the critical effects of acute inflammation secondary to diverticular perforation.

DCS is a well-established procedure in treating severely ill surgical patients suffering from traumatic and non-traumatic abdominal injuries. ${ }^{2-4}$ In the case of colonic diverticular perforation, DCS consists of a two-stage procedure: (first stage) perforated colon tract resection with blind oral and aboral closure, followed by lavage and temporary, vacuum-assisted abdominal wall closure; (second stage) scheduled second laparotomy after 24-48 hours with a decision about the definitive colon reconstruction (primary anastomosis with or without loop ileostomy vs Hartmann's procedure). ${ }^{2-4}$ In addition, further conditioning by continued bridging is possible with a vacuum dressing and definitive colon reconstruction after another 24-48 hours in the course of a possible "third look". ${ }^{2-4}$ Therefore, DCS should not be considered as a low invasiveness procedure. Moreover, we should keep in mind that DCS (in particular the "open abdomen") is associated with significant morbidity and high costs. ${ }^{1}$

In a recent update of their results, Sohn et $\mathrm{al}^{4}$ confirmed the benefits of DCS. However, in our opinion, an incorrect selection of patients persisted. Only $22 \%$ of DCS patients (16/74) met severe septic shock criteria. ${ }^{4}$ We do not agree with the authors' 
choice to subject the remaining non-septic population $(78 \%$; $58 / 74$ ) to DCS, a complex surgical procedure for real emergency situations.

Furthermore, out of 74 DCS patients, just 19\% (14/74) had Hinchey IV diverticulitis. ${ }^{4}$ Another reason for disagreement is as follows: DCS was applied in patients with nonfecal peritonitis (Hinchey III diverticulitis $=81 \%$; 60/74) and in the absence of evident severe septic shock in many of them. According to the pertinent literature, laparoscopic peritoneal lavage, a not yet recommended but much less invasive procedure, seemed to play a beneficial role in Hinchey III diverticulitis. ${ }^{5}$

Therefore, rather than abusing DCS, we would suggest the application of this procedure only in the presence of severely ill surgical (septic) patients in order to stop the detrimental effects of the inflammatory "lethal triad" (metabolic acidosis, hypothermia, and coagulopathy). In the absence of such clinical findings, we suggest the "classic" surgical treatment of acute perforated diverticulitis.
As suggested by Ceresoli et al, ${ }^{1}$ further studies are required to define indications, timing, and techniques of DCS for patients with non-traumatic abdominal injuries.

\section{Disclosure}

The authors report no conflicts of interest in this communication.

\section{References}

1. Ceresoli M, Lo Bianco G, Gianotti L, Nespoli L. Inflammation management in acute diverticulitis: current perspectives. I Inflamm Res. 2018;11:239-246.

2. Sohn M, Agha A, Heitland W, Gundling F, Steiner P, Iesalnieks I. Damage control strategy for the treatment of perforated diverticulitis with generalized peritonitis. Tech Coloproctol. 2016;20(8):577-583.

3. Zizzo M, Ugoletti L, Lococo F, Pedrazzoli C, Manenti A. Damage control surgery in patients with generalized peritonitis secondary to perforated diverticulitis: the risk of overtreatment. Tech Coloproctol. 2018;12:1-2.

4. Sohn MA, Agha A, Steiner P, et al. Damage control surgery in perforated diverticulitis: ongoing peritonitis at second surgery predicts a worse outcome. Int J Colorectal Dis. 2018;33(7):871-878.

5. Kohl A, Rosenberg J, Bock D, et al. Two-year results of the randomized clinical trial DILALA comparing laparoscopic lavage with resection as treatment for perforated diverticulitis. Br J Surg. 2018;16:1-7.

Dove Medical Press encourages responsible, free and frank academic debate. The content of the Journal of Inflammation Research 'letters to the editor' section does not necessarily represent the views of Dove Medical Press, its officers, agents, employees, related entities or the Journal of Inflammation Research editors. While all reasonable steps have been taken to confirm the content of each letter, Dove Medical Press accepts no liability in respect of the content of any letter, nor is it responsible for the content and accuracy of any letter to the editor.

\section{Publish your work in this journal}

The Journal of Inflammation Research is an international, peer-reviewed open access journal that welcomes laboratory and clinical findings on the molecular basis, cell biology and pharmacology of inflammation including original research, reviews, symposium reports, hypothesis formation and commentaries on: acute/chronic inflammation; mediators of inflammation; cellular processes; molecular mechanisms; pharmacology and novel anti-inflammatory drugs; clinical conditions involving inflammation. The manuscript management system is completely online and includes a very quick and fair peer-review system. Visit http://www.dove press.com/testimonials.php to read real quotes from published authors. 